\title{
Etiologic subtype predicts outcome in mild stroke: prospective data from a hospital stroke registry
}

\author{
Zilong Hao ${ }^{1}$, Ming Liu², Deren Wang ${ }^{1}$, Bo Wu', Wendan Tao ${ }^{1}$ and Xueli Chang ${ }^{1}$
}

\begin{abstract}
Background: Few studies on whether etiologic subtype can predict outcome in mild stroke are available. The study aim to explore the effect of different etiologic subtype on prognosis of these patients.

Methods: We prospectively registered consecutive cases of acute ischemic stroke from September. 01, 2009 to August. 31, 2011. Patients with National Institute of Health Stroke Scale (NIHSS) $\leqq 3$ and within 30 days of symptom onset were included. All cause death or disability (defined as modified Rankin Scale $>2$ ) were followed up at 3 months. The multivariate logistical regression model was used to analyse relationship between etiologic subtype and clinical outcomes.

Results: We included 680 cases, which accounted for $41.1 \%$ (680/1655) of the total registered cases. Mean age were $62.54 \pm 13.51$ years, and males were $65.4 \%$. The median time of symptoms onset to admission was 72 hours. $3.8 \%$ (26/680) of cases admitted within 3 hours and 4.7\% (32/680) admitted within 4.5 hours. However, no patient received intravenous thrombolysis. Of included patients, $21.5 \%$ large-artery atherosclerosis, $40.6 \%$ small-vessel disease, $7.5 \%$ cardioembolisms, $2.2 \%$ other causes and $28.2 \%$ undetermined causes. The rate of case fatality and death/disability was $2.2 \%$ and $10.1 \%$ respectively at 3 months. After adjustment of potential confounders, such as age, sex, NIHSS on admission and vascular risk factors et al., cardioembolism (RR $=3.395 ; 95 \% \mathrm{Cl} 1.257 \sim 9.170$ ) was the predictor of death or disability at 3 months and small vessel occlusion $(\mathrm{RR}=0.412 ; 95 \% \mathrm{Cl} 0.202 \sim 0.842)$ was the protective factor of death or disability at 3 months.
\end{abstract}

Conclusion: Different etiologic subtype can predict the outcome in patients with mild stroke and it can help to stratify these patients for individual decision-making.

Keywords: Acute ischemic stroke, Minor stroke, Etiology, Death/disability

\section{Background}

It is very common that acute ischemic stroke patients have mild symptoms or rapidly improving stroke symptoms, which makes the decisions of treatment in dilemma. Intravenous thrombolysis with recombinant tissue plasminogen activator (IV rtPA) is proven to be the most effective treatment for acute ischemic stroke $[1,2]$. However, only $1 \%-5 \%$ patients are treated with IV rtPA. In addition to the narrow time window for treatment, not treat patients with mild or rapidly improving symptoms is one important reason [3]. In studies evaluating eligibility for thrombolysis, up to $43 \%$ of patients

\footnotetext{
* Correspondence: wyplmh@hotmail.com

${ }^{2}$ From the Stroke Clinical Research Unit, Department of Neurology, State Key Laboratory of Biotherapy and Cancer Center, West China Hospital, Sichuan University, No 37, Guo Xue Xiang, Chengdu 610041, China

Full list of author information is available at the end of the article
}

with mild or improving stroke symptoms do not receive thrombolytic therapy because of clinicians think the natural course of these patients is benign [4]. However, according to recent reports, $15 \%-31 \%$ of patients with mild or rapidly improving symptoms have dependent or dead during hospital admission without thrombolysis [3,5-7]. Therefore, early identification of these patients with poor outcome will contribute to the choice of early intervention to prevent the occurrence of poor outcomes. Studies suggest that mild stroke patients with large vessel occlusion are at a high risk for early neurological deterioration or poor outcome [8]. Imaging with advanced MRI is one possibility to guide treatment decision in mild stroke [9-11]. Therapies directed at the underlying mechanism will be more effective. But there is still lack of clinical outcomes in patients with different 
etiologic subtype. This study aims to observe clinical characteristics and explore the effect of different etiologic subtype on prognosis of mild stroke.

\section{Methods \\ Subjects}

Due to this is an observational study that will only assess outcomes in participants, all participants or their designated relatives provided verbal informed consent for obtaining relative prognostic information. This research project was approved by the Scientific Research Department of West China Hospital, which conformed to the local ethic criteria for human researches. We included acute ischemic stroke admitted consecutively to neurological wards of the West China Hospital, Sichuan University within 30 days of symptom onset between September. 01, 2009 to August. 31, 2011. All patients had a clinical diagnosis of stroke according to World Health Organization (WHO) criteria and intracranial hemorrhage were further excluded by CT or MRI scan in the hospital [12]. Patients with National Institute of Health Stroke Scale (NIHSS) $\leqq 3$ were included [13] in this study.

\section{Data collection}

Details of patient demographies, vascular risk factors, Blood pressure (BP) on admission, laboratory test, brain image data and complications were recorded at the time of assessment using a standardized structured form. Vascular risk factors included hypertension (HTN), diabetes, dyslipidemia, coronary heart disease (CHD), history of stroke, status of smoking and alcohol. Severity of stroke was assessed using the NIHSS score. Medical complications include respiratory infection, urinary tract infection, electrolyte disturbances, hemorrhage of digestive tract and epilepsy. Determination of ischemic stroke etiology was according to the Trial of Org 10172 in Acute Stroke Treatment (TOAST) criteria: large-artery atherosclerosis (LAA); small artery occlusion (SAO); cardioembolism (CE); stroke of other determined cause (OC); and stroke of undetermined cause (UND) [14].

\section{Assessment of outcome}

The main outcomes were death and disability at 3 month after onset. Death was all-cause case fatality. Disability was defined as modified Rankin Scale $(\mathrm{mRS})>2$ [15]. Patients were followed-up by telephone call, clinic interview or letter inquiry. To ensure the quality of information collection, all investigators received training in the beginning according to our standard operational manual. All data were recorded in a structured data sheet. The outcome assessors were blinded to the information of patients. The poor outcome defined as death or disability $(\mathrm{mRS}>2)$ at 3 months.

\section{Statistical analysis}

Differences between two groups were tested using t test, Mann-Whitney U test or Chi-Square test where appropriate. Variables that were identified as significant in the univariate analyses $(\mathrm{P}<0.10)$ were entered into multivariate logistic regression analyses. The multivariate logistical regression was used to analyze association between different etiologic subtype and clinical outcomes, adjusting for all potential confounders including age, sex, NIHSS on admission, vascular risk factors and complications et al. Data are reported with Relative Risk (RR) and 95\% confidence intervals (CI). All statistical analyses were performed with SPSS for Windows, Version 16.0 (SPSS Inc.).

\section{Results}

\section{Baseline characteristics}

We included 1655 patients with acute ischemic stroke within 30 days of symptom onset. Of them, patients with mild stroke accounted for 41.1\% (680/1655). The mean age was $62.54 \pm 13.51$ years (18-97 years). Males accounted for $65.4 \%$ (445/680). The median time of symptoms onset to admission was 72 hours (2-270 hours). The median of NIHSS on admission is 2(1-3). Of these patients, $21.5 \%$ large-artery atherosclerosis, $40.6 \%$ smallvessel disease, $7.5 \%$ cardioembolisms, $2.2 \%$ other causes and $28.2 \%$ undetermined causes. $3.8 \%(26 / 680)$ of cases admitted within 3 hours and 4.7\% (32/680) admitted within 4.5 hours. However, no patient received rt-PA treatment. The common complications were $7.7 \%$ respiratory tract infection, $2.0 \%$ urinary tract infection, $2.2 \%$ electrolyte imbalances, $0.9 \%$ gastrointestinal bleeding and $0.4 \%$ secondary epilepsy. The proportion of case fatality and death/disability was $2.2 \%$ and $10.1 \%$ respectively at 3 months. In order to analyze the effect of specific etiology on prognosis of minor stroke, such as cardioembolisms, large-artery atherosclerosis, small-vessel disease, the patients with undetermined etiology were excluded from the following analysis. In addition, other causes were also excluded due to few patients were included in our study. So we keep a total of 453 cases for further analysis. Compared to patients without death or disability, patients with poor outcome were younger, had higher proportions of large-artery atherosclerosis or cardioembolisms and had high rate of complications of respiratory and urinary tract infection. Baseline characteristics of this cohort were described in Table 1.

\section{The influence of etiologic subtype on outcomes at 3 month}

After adjustment of potential confounders, such as age, sex, NIHSS on admission and vascular risk factors et al., cardioembolism was the independent predictor of death or disability at 3rdmonth ( $\mathrm{RR}=3.395 ; 95 \% \mathrm{CI} 1.257 \sim$ 
Table 1 Characteristics of patients with minor stroke according to outcomes

\begin{tabular}{|c|c|c|c|}
\hline Variates & $\begin{array}{l}\text { Death/ } \\
\text { disability } \\
\text { N1 = 43 }\end{array}$ & $\begin{array}{l}\text { No death/ } \\
\text { disability } \\
\text { N2 = } 373\end{array}$ & $P$ value \\
\hline Age, years & $68.84 \pm 10.03$ & $63.34 \pm 12.61$ & 0.006 \\
\hline Male, \% & 25(58.1) & 257(68.9) & 0.153 \\
\hline Time from onset, $h$ & 48 & 48 & 0.418 \\
\hline SBP on admission, mmHg & $141.88 \pm 25.96$ & $143.40 \pm 21.38$ & 0.667 \\
\hline DBP on admission, $\mathrm{mmHg}$ & $83.28 \pm 16.99$ & $84.13 \pm 13.64$ & 0.708 \\
\hline Hypertension, \% & $26(60.5)$ & $222(59.5)$ & 0.905 \\
\hline Diabetes mellitus, \% & $11(25.6)$ & $70(18.8)$ & 0.285 \\
\hline Dyslipidemia, \% & $3(7.0)$ & $31(8.3)$ & 1.000 \\
\hline Coronary heart diseas, \% & $2(4.7)$ & $22(5.9)$ & 1.000 \\
\hline History of ischemic stroke, \% & $1(2.3)$ & $22(5.9)$ & 0.493 \\
\hline History of hemorrhagic stroke & $2(4.7)$ & $3(0.8)$ & 0.086 \\
\hline Alcohol, \% & $6(14.0)$ & $80(20.3)$ & 0.251 \\
\hline Smoking, \% & $13(30.2)$ & 125(33.) & 0.665 \\
\hline TOAST classification & & & 0.055 \\
\hline LAA & $16(37.2)$ & $110(29.5)$ & \\
\hline SAO & 19(44.2) & $228(61.1)$ & \\
\hline CE & $8(18.6)$ & $35(9.4)$ & \\
\hline Respiratory infection, \% & $10(23.3)$ & $20(5.4)$ & 0.000 \\
\hline Urinary tract infection, \% & $3(7.0)$ & $5(1.3)$ & 0.040 \\
\hline Electrolyte disturbance, \% & $0(0.0)$ & $8(2.1)$ & 1.000 \\
\hline $\begin{array}{l}\text { Hemorrhage of digestive } \\
\text { tract,\% }\end{array}$ & $1(2.3)$ & $3(0.8)$ & 0.355 \\
\hline Epilepsy, \% & $1(2.3)$ & $1(0.3)$ & 0.196 \\
\hline
\end{tabular}

LAA: large-artery atherosclerosis.

SAO: small artery occlusion.

CE: cardioembolism.

9.170) (Table 2). Small vessel occlusion also was the independent predictor of good outcome at 3rd month $(\mathrm{RR}=0.412 ; 95 \% \mathrm{CI} 0.202 \sim 0.842)$ (Table 3). Large-artery atherosclerosis was not the independent predictor of death or disability, but had a trend of increasing death/ disability ( $R R=1.497$; 95\%CI $0.723 \sim 3.102$ ) (data not shown). In addition, age, history of intracerebral hemorrhage and complications were independent predictive factor for death or disability at 3rd month across different etiologic subtype analysis.

\section{Discussion}

In this study, we found patients with mild stroke accounted for $41.1 \%$ in our cohort. The proportion of case fatality and death/disability was $2.2 \%$ and $10.1 \%$ respectively at 3 month. Different etiologic subtype can predict the outcome in these patients.

Previous studies showed the proportion of mild stroke veried from $5.8 \%$ to $62.3 \%$ based on different criteria, which in accordance with our study $[16,17]$. Khatri et al.
Table 2 Multivariate logistic analysis of the influence of cardioembolism on death/disability

\begin{tabular}{llll}
\hline Variates & RR & $\mathbf{9 5 \% ~ C l}$ & P value \\
\hline Age & 1.037 & $1.003 \sim 1.073$ & .031 \\
Gender & .628 & $.276 \sim 1.426$ & .266 \\
Time from onset & 1.002 & $1.000 \sim 1.004$ & .107 \\
SBP on admission & .992 & $.969 \sim 1.015$ & .486 \\
DBP on admission & 1.008 & $.972 \sim 1.045$ & .668 \\
Hypertension & 1.313 & $.610 \sim 2.826$ & .486 \\
Diabetes mellitus & 1.263 & $.533 \sim 2.989$ & .596 \\
Hypercholesterolemia & 1.188 & $.317 \sim 4.448$ & .798 \\
Coronary heart diseas & .321 & $.060 \sim 1.708$ & .183 \\
History of ischemic stroke & .228 & $.025 \sim 2.070$ & .189 \\
History of hemorrhagic stroke & 11.297 & $1.469 \sim 86.889$ & .020 \\
Alcohol & .619 & $.208 \sim 1.848$ & .390 \\
Smoking & 1.620 & $.644 \sim 4.072$ & .305 \\
CE VS. Non-CE & 3.395 & $1.257 \sim 9.170$ & .016 \\
Complications & 3.405 & $1.527 \sim 7.596$ & .003 \\
\hline CE: cardioembolism. & & &
\end{tabular}

suggests that approximately one third of so-called mild strokes have significant disability (mRS 2-6) that persists at 3 months [7]. In contrast, we found $10.1 \%$ of minor stroke had death or disability. The reasons of low proportion of our study may be as follows: (1) they used the NIHSS $\leqq 5$ as criteria whereas we used NIHSS $\leqq 3$, which indicates they included participants more severer than ours; (2) they measured disability with $\mathrm{mRS}>1$ whereas we defined it as $\mathrm{mRS}>2$; (3) they enrolled patients

Table 3 Multivariate logistic analysis of the influence of SAO on death/disability

\begin{tabular}{llll}
\hline Variates & RR & $\mathbf{9 5 \%} \mathbf{C l}$ & P value \\
\hline Age & 1.035 & $1.002 \sim 1.069$ & .039 \\
Gender & .614 & $.270 \sim 1.398$ & .245 \\
Time from onset & 1.001 & $.999 \sim 1.003$ & .306 \\
SBP on admission & .987 & $.965 \sim 1.010$ & .256 \\
DBP on admission & 1.014 & $.978 \sim 1.051$ & .449 \\
Hypertension & 1.428 & $.659 \sim 3.095$ & .367 \\
Diabetes mellitus & 1.276 & $.536 \sim 3.041$ & .582 \\
Hypercholesterolemia & 1.114 & $.301 \sim 4.124$ & .871 \\
Coronary heart diseas & .437 & $.088 \sim 2.170$ & .311 \\
History of ischemic stroke & .265 & $.029 \sim 2.425$ & .240 \\
History of hemorrhagic stroke & 12.420 & $1.423 \sim 108.367$ & .023 \\
Alcohol & .628 & $.209 \sim 1.886$ & .407 \\
Smoking & 1.600 & $.630 \sim 4.063$ & .323 \\
SAO vS. Non-SAO & .412 & $.202 \sim .842$ & .015 \\
Complications & 3.477 & $1.536 \sim 7.869$ & .003 \\
\hline SAO small arter occlusion & & &
\end{tabular}

SAO: small artery occlusion. 
within 24 hours whereas we included them within 30 days, which means their participants may be prone to have early worsening or early recurrence than ours; (4) In general, the death or disability of acute ischemic stroke patients in China is lower than abroad $[18,19]$, so may be minor stroke no exception.

Several studies reported the predictors of poor outcome of mild stroke, such as age, diabetes, coronary heart disease, smoking, and vessel stenosis or occlusion were predictor of death or disability or recurrence at the end of follow up period [20-25]. Ferrari J et al. found hypertension, diabetes, cardiac decompensation, acute infection, and stroke etiology (LAA and CE) emerged as independent risk predictors for early deterioration in patients with a transient ischaemic attack (TIA) or minor ischemic stroke, defined by an NIHSS score <4 [26]. In our cohort, age, history of intracerebral hemorrhage, infections and etiologic subtype (CE and SAO) were the independent predictors of death or disability at 3rd month. Our finding of etiologic subtype can predict outcome in mild stroke is more compelling, because consecutive subjects that were assessed beyond hospital discharge at 90 days. So far, although there are no identical variates for predicting the poor outcome of patients with minor stroke, future studies are needed to focus on how to really identify minor stroke patients with poor outcome by clinical features combined with imaging features. Recently, Strbian D et al. indicates that half of patients presenting with NIHSS 0-6 developed an infarction despite thrombolysis, and $40 \%$ had poor outcome. Perhaps, urgent multimodal imaging can help to identify mild stroke at risk of worsening [27]. As we known, etiologic subtype help stratify patients for secondary prevention and it may also be used for identifing poor outcome in patients with mild stroke.

At present, whether patients presenting with mild stroke should or should not be treated with intravenous rtPA is still unclear. In our study, 3.8\% (26/680) of cases admitted within 3 hours and 4.7\% (32/680) admitted within 4.5 hours. However, no patient received intravenous thrombolysis. In the light of the natural history of course of mild stroke is not always benign, before a large randomized trial proving its lack of benefit in mild stroke patients, IV t-PA should be considered in these patients.

Our study has several limitations. (1) It was performed in a single-center, which may not represent for whole Chinese population; (2) there is no consensus definition of mild stroke. The National Institute of Neurological Disorders and Stroke (NINDS) rtPA study and the European Cooperative Acute Stroke Study (ECASS) III both excluded patients with mild stroke, but they failed to clearly define a certain threshold for a mild stroke. We used diagnostic criteria NIHSS score $\leqq 3$, which be evaluated as the more suitable cutoff point [13]; (3) The effects of potential unknown confounders cannot be ruled out in our cohort. Despite these limitations, our study explored the relationship between etiologic subtype and outcomes by inclusion of propectively consecutive patients and the blind evaluation of the study outcome.

\section{Conclusions}

In conclusion, our study indicates that different etiologic subtype can predict the outcome in patients with minor stroke it can help to stratify these patients for individual decision-making.

\section{Abbreviations}

IV rtPA: Intravenous thrombolysis with recombinant tissue plasminogen activator; WHO: World Health Organization; NIHSS: National Institute of Health Stroke Scale; BP: Blood pressure; HTN: Hypertension; CHD: Coronary heart disease; TOAST: Trial of Org 10172 in Acute Stroke Treatment; LAA: Large-artery atherosclerosis; SAO: Small artery occlusion;

CE: Cardioembolism; OC: Stroke of other determined cause; UND: Stroke of undetermined cause; mRS: modified rankin scale; TIA: Transient ischaemic attack; NINDS: National Institute of Neurological Disorders and Stroke; ECASS: European Cooperative Acute Stroke Study.

\section{Competing interests}

The authors declare that they have no competing interests.

\section{Authors' contributions}

ZH was responsible for the conception and design of the study, data collection, data analysis and interpretation, drafting and revising the manuscript. ML was responsible for the conception and design of the study, data analysis and interpretation, and revising the manuscript. DW, BW, WT and XC were responsible for data collection, revising the manuscript. All authors have read and approved the final manuscript.

\section{Sources of funding}

This research was supported by the Science and technology infrastructure projects of Sichuan Province (NO.2012JCPT008) and the Science \& Technology Program of Science and Technology Department of Sichuan Province (No. 2011SZ0202)

\section{Author details}

${ }^{1}$ From the Stroke Clinical Research Unit, Department of Neurology, West China Hospital, Sichuan University, No 37, Guo Xue Xiang, Chengdu 610041 China. ${ }^{2}$ From the Stroke Clinical Research Unit, Department of Neurology, State Key Laboratory of Biotherapy and Cancer Center, West China Hospital, Sichuan University, No 37, Guo Xue Xiang, Chengdu 610041, China.

Received: 3 May 2013 Accepted: 15 October 2013

Published: 24 October 2013

\section{References}

1. Tissue plasminogen activator for acute ischemic stroke. The national institute of neurological disorders and stroke rt-PA stroke study group. $N$ Engl J Med 1995, 333(24):1581-1587.

2. Hacke W, Kaste M, Bluhmki E, Brozman M, Davalos A, Guidetti D, Larrue V, Lees KR, Medeghri Z, Machnig T, et al: Thrombolysis with alteplase 3 to 4.5 hours after acute ischemic stroke. N Engl J Med 2008, 359(13):1317-1329.

3. Barber PA, Zhang J, Demchuk AM, Hill MD, Buchan AM: Why are stroke patients excluded from TPA therapy? An analysis of patient eligibility. Neurology 2001, 56(8):1015-1020.

4. Kleindorfer D, Kissela B, Schneider A, Woo D, Khoury J, Miller R, Alwell K, Gebel J, Szaflarski J, Pancioli A, et al: Eligibility for recombinant tissue plasminogen activator in acute ischemic stroke: a population-based study. Stroke 2004, 35(2):e27-29. 
5. Ohara T, Nagakane Y, Tanaka E, Morii F, Koizumi T, Yamamoto Y: Clinical and radiological features of stroke patients with poor outcomes Who Do Not receive intravenous thrombolysis because of mild symptoms. Eur Neurol 2013, 69(1):4-7.

6. Smith EE, Fonarow GC, Reeves MJ, Cox M, Olson DM, Hernandez AF, Schwamm LH: Outcomes in mild or rapidly improving stroke not treated with intravenous recombinant tissue-type plasminogen activator: findings from Get with the guidelines-stroke. Stroke 2011 42(11):3110-3115.

7. Khatri P, Conaway MR, Johnston KC: Ninety-day outcome rates of a prospective cohort of consecutive patients with mild ischemic stroke. Stroke 2012, 43(2):560-562

8. Nedeltchev K, Schwegler B, Haefeli T, Brekenfeld C, Gralla J, Fischer U, Arnold M, Remonda L, Schroth G, Mattle HP: Outcome of stroke with mild or rapidly improving symptoms. Stroke 2007, 38(9):2531-2535.

9. Coutts SB, Simon JE, Eliasziw M, Sohn CH, Hill MD, Barber PA, Palumbo V, Kennedy J, Roy J, Gagnon A, et al: Triaging transient ischemic attack and minor stroke patients using acute magnetic resonance imaging. Ann Neurol 2005, 57(6):848-854.

10. Rajajee $V$, Kidwell C, Starkman S, Ovbiagele B, Alger JR, Villablanca P, Vinuela F, Duckwiler G, Jahan R, Fredieu A, et al: Early MRI and outcomes of untreated patients with mild or improving ischemic stroke. Neurology 2006, 67(6):980-984

11. Desilles JP, Cho TH, Hermier M, Mechtouff-Cimarelli L, Derex L, Nighoghossian N: Magnetic resonance imaging-guided thrombolysis in minor stroke. Int J Stroke 2011, 6(2):178.

12. Stroke-1989: Recommendations on stroke prevention, diagnosis, and therapy. Report of the WHO task force on stroke and other cerebrovascular disorders. Stroke 1989, 20(10):1407-1431.

13. Fischer U, Baumgartner A, Arnold M, Nedeltchev K, Gralla J, De Marchis GM, Kappeler L, Mono ML, Brekenfeld C, Schroth G: What is a minor stroke? Stroke 2010, 41(4):661-666.

14. Adams HP Jr, Bendixen BH, Kappelle LJ, Biller J, Love BB, Gordon DL, Marsh EE 3rd: Classification of subtype of acute ischemic stroke. Definitions for use in a multicenter clinical trial. TOAST. Trial of Org 10172 in acute stroke treatment. Stroke 1993, 24(1):35-41.

15. van Swieten JC, Koudstaal PJ, Visser MC, Schouten HJ, van Gijn J: Interobserver agreement for the assessment of handicap in stroke patients. Stroke 1988, 19(5):604-607.

16. Atanassova PA, Chalakova NT, Dimitrov BD: Major vascular events after transient ischaemic attack and minor ischaemic stroke: post hoc modelling of incidence dynamics. Cerebrovasc Dis 2008, 25(3):225-233.

17. Ogata T, Yasaka M, Wakugawa Y, Ibayashi S, Okada Y: Predisposing factors for acute deterioration of minor ischemic stroke. J Neurol Sci 2009, 287(1-2):147-150

18. CAST: randomised placebo-controlled trial of early aspirin use in 20,000 patients with acute ischaemic stroke. CAST (Chinese acute stroke trial) collaborative group. Lancet 1997, 349(9066):1641-1649.

19. Huang Y, Wang JG, Wei JW, Headley AP, Wong LK, Heeley EL, Arima H, Sun J, Li Q, Liu M: Age and gender variations in the management of ischaemic stroke in China. Int J Stroke 2010, 5(5):351-359.

20. Prencipe M, Culasso F, Rasura M, Anzini A, Beccia M, Cao M, Giubilei F, Fieschi C: Long-term prognosis after a minor stroke: 10-year mortality and major stroke recurrence rates in a hospital-based cohort. Stroke 1998, 29(1):126-132

21. Selvarajah JR, Smith CJ, Hulme S, Georgiou RF, Vail A, Tyrrell PJ: Prognosis in patients with transient ischaemic attack (TIA) and minor stroke attending TIA services in the North West of England: the NORTHSTAR Study. J Neurol Neurosurg Psychiatry 2008, 79(1):38-43.

22. van Wijk I, Kappelle LJ, van Gijn J, Koudstaal PJ, Franke CL, Vermeulen M, Gorter JW, Algra A: Long-term survival and vascular event risk after transient ischaemic attack or minor ischaemic stroke: a cohort study. Lancet 2005, 365(9477):2098-2104.

23. Kim JT, Kim HJ, Yoo SH, Park MS, Kwon SU, Cho KH, Kim JS, Kang DW: MRI findings may predict early neurologic deterioration in acute minor stroke or transient ischemic attack due to intracranial atherosclerosis. Eur Neurol 2010, 64(2):95-100

24. Coutts SB, Hill MD, Campos CR, Choi YB, Subramaniam S, Kosior JC, Demchuk AM: Recurrent events in transient ischemic attack and minor stroke: what events are happening and to which patients? Stroke 2008, 39(9):2461-2466.
25. Coutts SB, Modi J, Patel SK, Demchuk AM, Goyal M, Hill MD: CT/CT angiography and $\mathrm{MRI}$ findings predict recurrent stroke after transient ischemic attack and minor stroke: results of the prospective CATCH study. Stroke 2012, 43(4):1013-1017.

26. Ferrari J, Knoflach M, Kiechl S, Willeit J, Schnabl S, Seyfang L, Lang W: Early clinical worsening in patients with TIA or minor stroke: the Austrian stroke unit registry. Neurology 2010, 74(2):136-141.

27. Strbian D, Piironen K, Meretoja A, Sairanen T, Putaala J, Tiainen M, Artto V, Rantanen K, Happola O, Kaste M: Intravenous thrombolysis for acute ischemic stroke patients presenting with mild symptoms. Int J Stroke 2013, 8(5):293-299.

doi:10.1186/1471-2377-13-154

Cite this article as: Hao et al:: Etiologic subtype predicts outcome in mild stroke: prospective data from a hospital stroke registry. BMC Neurology 2013 13:154.

\section{Submit your next manuscript to BioMed Central and take full advantage of:}

- Convenient online submission

- Thorough peer review

- No space constraints or color figure charges

- Immediate publication on acceptance

- Inclusion in PubMed, CAS, Scopus and Google Scholar

- Research which is freely available for redistribution

Submit your manuscript at www.biomedcentral.com/submit
C BioMed Central 